\title{
Leading Economic Indicators
}

Movements in the Index of Leading Economic Indicators (ILI), compiled by the Department of Commerce, typically garner front-page attention. Every wiggle is analyzed by government and business economists for signals about the future health of the economy with good reason. Each post-war business cycle peak (and trough) has been preceded by a significant decline (and rise) in the ILI. The current recovery is no exception: eight months prior to the beginning of the upswing in December 1982, the index of leading economic indicators began to rise.

\section{"Noise" and news}

There are, however, at least two difficulties with using the index as a forecasting aid. The first is that, except with the benefit of sufficiently long hindsight, it is often difficult to judge at the time it occurs whether an upturn or downturn in the index will be sustained. The index often exhibits short-term swings that are soon reversed. Since May 1984, for example, the ILI has changed direction six times. To filter out this "noise" in the numbers, analysts often apply rules-of-thumb. A common rule is that a change in the direction of the index lasting at least three consecutive months constitutes a signal of recession or recovery to come. On this basis, initial estimates of the index in 1984 signalled a recession - they declined in June, July and August. But justreleased revisions of the index now show that it rose in August. Thus, there were only two consecutive months of decline rather than three.

The second difficulty in interpreting the ILI is that the future it may help to predict is somewhat indefinitely far ahead. Major downturns in the ILI, for example, have occurred anywhere from three to twenty-three months ahead of actual downturns. Upturns in the index have started from one to eight months before the economy bottomed out. The problems of judging sustained changes in the index and of the relatively short average leadtime between turns in the index and turns in the economy (particularly for troughs) have led some analysts to argue that the principal value of the ILI lies in its ability to identify the current state of the economy. Since much economic data are available only after the fact and since they often are subject to substantial revisions, even being able to "predict" the present is valuable.

\section{Construction of ILI}

Despite these reservations, the ILI has the advantage of diversification: it is a composite index made up of many different series. Movements in economic activity originate from different sources at different times and the response of the economy to any given stimulus may itself vary over time. By including a wide range of series covering many different activities, the composite index is more likely to detect important changes in the level of aggregate economic activity, regardless of the source of those movements.

From time to time, the series used to construct the ILI have changed. The last major revision took place in 1975 when a number of series were specified in real, or constant dollar, terms rather than in current dollar terms. Since then, new weights have been assigned to the individual series in light of past experience, and the definitions of some of the series have changed. The twelve series currently used to construct the composite index were selected on the basis of six criteria: (1) economic significance, (2) statistical adequacy, (3) consistency of timing at business cycle peaks and troughs, (4) conformity to the business cycle generally, (5) smoothness, and (6) prompt availability of data.

The significance criterion emphasizes series that represent what are thought to be important sources of business cycle movements. Statistical adequacy requires that the available data series faithfully measure movements in those sources. The requirement of consistency focuses attention on series that have reliably turned upward and downward prior to troughs and peaks in overall economic activity. Conformity refers to how consistently a series moves with the overall pattern of activity, not just at business cycle turning points. The smoothness criterion gives emphasis to series whose changes in direction are likely to be maintained. And the availability criterion ensures that the data for the series are available soon after the fact. 
The different series reflect developments in many areas of the economy: in labor markets (new unemployment insurance claims, average weekly hours in manufacturing); in financial markets (common stock prices, real money supply, percent change in private credit); in residential construction (new building permits); in business activity (net business formation, real value of contracts and orders for plant and equipment, change in real inventories on hand and on order, real value of new orders for consumer goods, percent of companies receiving slower deliveries); and in prices (percent change in sensitive materials prices).

The recent surge in U.S. imports provides a vivid example of why a broadly based ILI generally provides better signals than any one of its component series. Import penetration has been concentrated in goods rather than services. (It's not difficult for Americans to buy French autos; it is more difficult to buy French taxi rides, unless one goes to France.) This has been especially true in the business equipment industry. About onequarter of total expenditures by domestic business for durables recently has been for foreign items. Thus, looking at orders alone would suggest weakness in the U.S. economy.

This, however, is not the case. The strength of demand from other sources has overwhelmed the depressing effects on the economy of the import surge. Because the ILI includes non-orders series as well as orders series, it accurately reflects this strength in the economy. (In fact, through its effects on interest rates and the dollar exchange rate, the strength of demand in these other sectors has contributed to the surge in imports.)

\section{Inflation and supply shocks}

The ILI's component series were selected primarily on the basis of their records over the 1947-70 period. Peacetime business cycles in that period took place in an environment of low inflation, and were driven primarily by "shocks" to aggregate domestic spending as government and private sector behavior shifted. Since 1970, the American economy has also been buffeted by disturbances in aggregate supply and by shocks originating externally. Moreover, since the late 1960 s, the underlying and observed rates of inflation have been through three cycles: the late 1960 s rise that culminated in a fall when price controls were imposed in 1971; the mid-1970s rise brought on by OPEC, and the subsequent fall; and the rise in the late 1970s, again associated with OPEC, and the dramatic decline since 1980. These alternating periods of relatively high and low inflation make interpretation of the index as currently constructed problematic.

The level of common stock prices, percent changes in sensitive materials prices, and percent changes in private credit are three series included in the index that can distort the index as an indicator of real activity because they are not adjusted for changes in the overall level of prices. When variations in the inflation rate are relatively small, these distortions are relatively unimportant. But suppose there were a sudden large drop in inflation from an average rate of ten percent to five percent. After the adjustments to this new situation, materials prices and credit growth rates each would be five percent lower than before. Although these lower growth rates would not indicate weaker real growth in the demand for or supply of materials or credit, their inclusion in the ILI would tend to depress the level of the index.

Similarly, the Standard and Poor's 500 stock price index enters the ILI in units unadjusted for the higher level of aggregate prices. If stock prices generally rise one-for-one with the aggregate price level, the unadjusted stock price index would rise, other things being equal, at the rate of inflaton. This will tend unduly to elevate the ILI even if the real value of equities is unchanged. In the post-1980 period, when inflation slowed dramatically but the price level continued to rise, the effects of these forces would presumably have tended to offset each other to an unknown extent.

Even adjusting materials price inflation for general inflation may not convert it into a reliable signal when there are shocks to aggregate supply as well as to aggregatedemand. If there were only demand shocks, the inflation-adjusted, or relative, price of materials may bear a consistent relation to aggregate economic activity. For example, if such prices rose quickly and generally in advance of increases in aggregate demand and output, they would put upward pressure on the ILI. However, if there were a disturbance that reduced the supply of raw materials, the relative price of this supply would also rise, but tend to be associated with lower economic activity. In this case, the ILI again would show an increase even though economic activity would have weakened. This is what happened both in the middle and late 1970s when the world 
price of oil skyrocketed. The possibility of simultaneous supply and demand shocks makes it difficult to interpret what movements in this component imply about the future state of the economy without supplementary information on the source of such movements.

\section{An alternative index}

The chart plots the official ILI and an alternative that makes a rough attempt to compensate for the fact that the rates of change in materials prices and in private credit in the index are not adjusted for inflation. As explained earlier, a decline in the economy-wide rate of inflation - such as occurred in 1983-84 - would show up as a fall in the ILI, even though economic activity might be unaffected. To remove this anomaly, the new series adjusts the index upward to offset the decline caused by falling inflation. In other words, it is what the index would be if the core, or underlying, inflationary rate had not changed. Since the underlying inflation rate fell an average of 0.1 percent each month in the period 1983-1984, the adjustment consists of adding successive increments of 0.1 percent each month to the rates of growth of materials prices and credit over the period, and then re-computing the ILI on the basis of these new series. Since the actual inflation rate has fallen even further than the core rate, using the actual rate to adjust the index would provide an even bigger boost to the alternative index. Deflating the level of stock prices, on the other hand, would move the alternative index closer to the official index.

The alternative index rises three percent more than the official index over this short period, and although both measures reached their highest levels last May, the alternative index had virtually
Has the Index of Leading Indicators Receded?

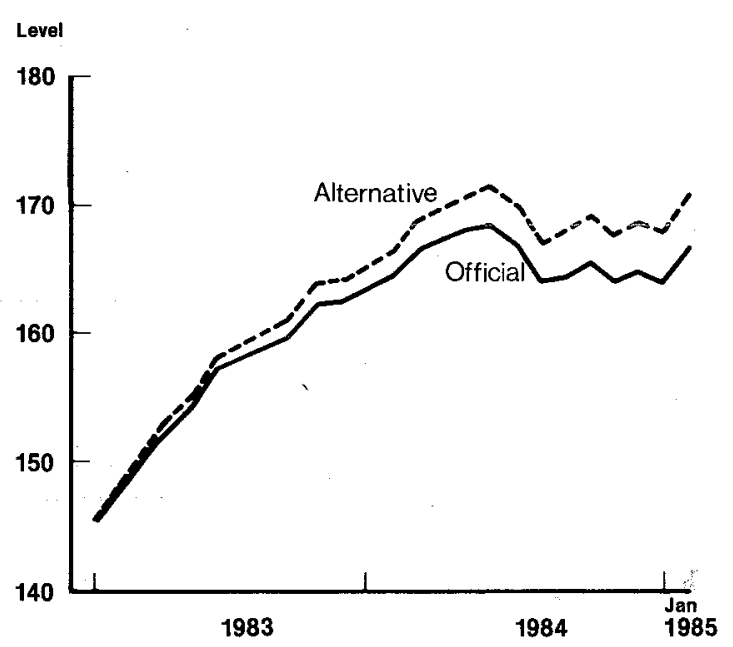

reattained its peak level by January, while the official index remained somewhat below its peak.

Thus, the alternative index suggests that the official index may not be issuing a sufficiently optimistic signal about the upcoming condition of the economy. As long as the inflation rate declines, the divergence between the two measures will increase. Over periods as brief as a couple of months, these two indexes are likely to behave similarly because the majority of their component series are specified in real terms, that is to say, abstracting of inflation. Only sizeable changes in the prevailing inflation rate, which usually take a number of months to occur, will lead to noticeable differences. But even without modifications for the effects of changing inflation rates, the index of leading economic indicators still provides valuable information about the future state of the economy.

James A. Wilcox 
voj6u!ysom yozก vobajo oponau

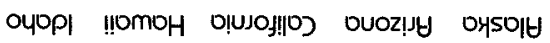

OSIDUOJ UOS

jo YणOg

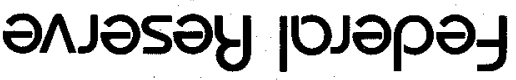

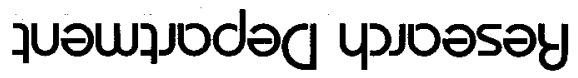

BANKING DATA-TWELFTH FEDERAL RESERVE DISTRICT

(Dollar amounts in millions)

\begin{tabular}{|c|c|c|c|c|}
\hline \multirow{2}{*}{$\begin{array}{l}\text { Selected Assets and Liabilities } \\
\text { Large Commercial Banks }\end{array}$} & \multirow{2}{*}{$\begin{array}{c}\text { Amount } \\
\text { Outstanding } \\
03 / 13 / 85\end{array}$} & \multirow{2}{*}{$\begin{array}{c}\text { Change } \\
\text { from } \\
03 / 06 / 85 \\
\end{array}$} & \multicolumn{2}{|c|}{$\begin{array}{l}\text { Change from } \\
03 / 14 / 84\end{array}$} \\
\hline & & & Dollar & Percent ${ }^{7}$ \\
\hline Loans, Leases and Investments ${ }^{1} 2$ & 188,847 & 110 & 12,700 & 7.2 \\
\hline Loans and Leases 16 & 171,109 & 120 & 15,072 & 9.6 \\
\hline Commercial and Industrial & 52,880 & & 5,775 & 12.2 \\
\hline Real estate & 62,269 & 38 & 2,455 & 8.2 \\
\hline Loans to Individuals & 32,889 & 87 & 5,799 & 21.4 \\
\hline Leases & 5,328 & 43 & 322 & 6.4 \\
\hline U.S. Treasury and Agency Securities ${ }^{2}$ & 10,662 & 37 & 1,543 & -12.6 \\
\hline Other Securities ${ }^{2}$ & 7,075 & 26 & 825 & -10.4 \\
\hline Total Deposits & 193,357 & -910 & 7,559 & 4.1 \\
\hline Demand Deposits & 44,096 & -768 & 575 & 1.3 \\
\hline Demand Deposits Adjusted ${ }^{3}$ & 29,772 & -79 & 478 & 1.6 \\
\hline Other Transaction Balances 4 & 13,265 & 313 & 980 & 7.9 \\
\hline Total Non-Transaction Balances ${ }^{6}$ & 136,000 & 172 & 6,004 & 4.6 \\
\hline \multicolumn{5}{|l|}{ Money Market Deposit } \\
\hline Accounts - Total & 49,952 & 57 & 3,457 & 8.5 \\
\hline $\begin{array}{c}\text { Time Deposits in Amounts of } \\
\$ 100,000 \text { or more }\end{array}$ & 38,979 & 70 & 901 & 2.3 \\
\hline Other Liabilities for Borrowed Money ${ }^{5}$ & 19,767 & 1,059 & 919 & 4.8 \\
\hline $\begin{array}{l}\text { Two Week Averages } \\
\text { of Daily Figures }\end{array}$ & $\begin{array}{l}\text { Period ended } \\
03 / 11 / 85\end{array}$ & \multicolumn{3}{|c|}{$\begin{array}{l}\text { Period ended } \\
02 / 25 / 85\end{array}$} \\
\hline \multicolumn{5}{|l|}{ Reserve Position, All Reporting Banks } \\
\hline Excess Reserves (+)/Deficiency (-) & 63 & \multicolumn{3}{|c|}{111} \\
\hline Borrowings & 32 & \multicolumn{3}{|c|}{84} \\
\hline Net free reserves $(+) /$ Net borrowed(-) & 30 & \\
\hline
\end{tabular}

1 Includes loss reserves, unearned income, excludes interbank loans

2 Excludes trading account securities

3 Excludes U.S. government and depository institution deposits and cash items

4 ATS, NOW, Super NOW and savings accounts with telephone transfers

5 Includes borrowing via FRB, TT\&L notes, Fed Funds, RPs and other sources

6 Includes items not shown separately

7 Annualized percent change 